\title{
Could Maggot Therapy be taught in Primary
}

\section{Schools?}

\author{
Humphreys $\mathrm{I}^{1}$ Lehane $\mathrm{P}^{2}$, Nigam $\mathrm{Y}^{3 *}$
}

Job title and Addresses:

Ioan Humphreys - Research Co-ordinator (Health and Wellbeing Academy) College of Human and Health Sciences, Swansea University, SA2 8PP, UK

Paula Lehane - PhD candidate; Centre for Assessment Research, Policy and Practice in Education, Dublin City University, Dublin 9, Ireland

Yamni Nigam* - Professor (Biomedical Science), Lead of Swansea University Maggot Research Group, College of Human and Health Sciences, Swansea University, SA2 8PP, UK

* Corresponding author - y.nigam@swansea.ac.uk 


\section{Abstract}

We conducted a small pilot study examining the opinions of school teachers across five Welsh Primary schools on the possibility of introducing grand challenges (such as antibacterial resistance), and concepts to help solve such challenges (such as the use of living maggots to help treat infected wounds) to pupils at a young age. Our questionnaire-based study found that most teachers felt that this was indeed possible, with the majority feeling that pupils in Years 5 and 6 would be the most relevant and best years in which to introduce these concepts. With regards to introducing maggots to children as being positive and beneficial creatures, almost $50 \%$ of teachers felt that squeamishness may be present in children of all years, but that disgust and dislike of maggots would exist to a greater degree in older children. Our exploratory results suggest that with further research, this important biological concept could be introduced in the curriculum of primary schools, when perhaps less engrained negative perceptions, and more educated awareness of the positive benefits of using maggots as a treatment for wound infections may be achievable.

\section{Key words}

Maggots; Maggot Therapy; antibacterial resistance; Wound infection, Primary school Years 1-6 


\section{Introduction}

The innovative New Curriculum for Wales is in its final stages of development for settings and schools in Wales. It was released in April 2019 to two hundred primary schools with complete rollout planned throughout Wales by 2022 . The curriculum will apply to both English-speaking and Welsh-Medium State Schools The curriculum offers exciting opportunities for all pupils across all years, essentially enveloping a learner centric mode of teaching with clearly defined areas of learning and experience (AoLEs). Within such areas such as health and well-being, the organism and the environment, there is scope to introduce students to several of the grand challenges that the world's population faces. One such grand challenge is the rise of antibiotic resistance, bought on by the over use of antibiotics (Ventola 2015). The WHO has noted that antibiotic resistance is the biggest threat to food security, health and development (WHO website https://www.who.int/news-room/fact-sheets/detail/antibioticresistance) and spearheads a world antibiotic awareness week every year. Antibiotic resistance is a particular problem for people with chronic wounds, such as diabetic leg ulcers, where their wounds don't respond to antibiotic courses and may result in amputation in the most serious cases. There is, however, a therapy available on the NHS that can combat this, this is Maggot therapy (MT) - the clinical application of living, baby maggots onto an infected, chronic wound bed. Maggot Therapy is a clinically recognised and scientifically proven intervention (Dumville et al, 2009; Sherman 2014; Malekian et al, 2019) and works efficiently to manage the clearing and cleansing of stagnant infected wounds (Gieroń, et al 2018;Yan et al, 2018), which can often result from conditions such as diabetes and blood circulation disorders. 
Despite the escalating abundance of clinical and scientific evidence supporting the viability and effectiveness of MT, adult public awareness and acceptance of this treatment is low and the general perception of maggots is inherently negative. Previous literature (Steenvoorde et al 2005; Jones et al 2011; Sandelowski 2010), and our own research findings (In Submission), support the fact that there is the existence of a "Yuck Factor", a perceived squeamishness and disgust of maggots. Invertebrates, in general, have a 'bad perception' amongst the general public (Lorenz et al 2014, Borgi \& Cirulli 2015, Fancovicova \& Prokop 2018). Bees, however, are generally accepted and liked by the public (Sumner at al 2018). Relevant to the present study, Davey (1994) ranked maggots as 6th out of 35 in terms of animals that caused anxiety in a cohort of university students. This "Yuck Factor" acts as a significant barrier to the wider adoption and use of this therapy among the general population.

Feeling disgust/dislike towards a particular object or organism though is not always innate. For example, somewhere within childhood, people may begin to learn that maggots are creatures related to acts of decomposition and decay. As a result, a negative perception of them is developed, which appears to persist into adulthood. But what if maggots and their medicinal properties were introduced to pupils in primary schools, perhaps as part of the WHO antibiotic awareness week? Could early education and knowledge for school-age children help combat the "Yuck Factor" in future generations? We know, through analysis and feedback from our Love a maggot Campaign (www.loveamaggot.com) that perception and attitudes towards maggots and maggot therapy can change for the positive once people are presented with the evidence base for the use of maggot therapy (In Submission). Research has found that children tend to show preferences for animals sharing 
certain similarities with humans (Prokop and Randler 2018). It has been shown, however, that having lessons where children have 'hands-on' experience with animals such as wood lice, snails and mice has reduced the disgust and fear students had before they started the lesson (Randler et al 2012, Fančovičová, \& Prokop (2017), Wust-Ackermann et al 2018). Therefore, teachers would need to introduce maggots to their students in a fun and enjoyable way that eliminates or at least mitigates their feelings of disgust for these creatures.

Any change to a curriculum can be considered an educational innovation (Rekkor, et al 2013). Therefore, the potential introduction of MT into the updated Welsh curriculum can be viewed through the lens of Rogers' (1995) Diffusion of Innovations theory. This theoretical framework defines innovation as 'any idea, practice or object that is perceived as new by an individual or other unit of adoption' (Rogers, 1995, p. 162). As a result, Rogers' (1995) Diffusion of Innovations theory was used as a framework in the current study to better understand the feasibility of teaching MT in schools and what conditions would need to be in place to maximise the likelihood that this innovative approach to teaching the Welsh curriculum would be adopted by schools in the future. Figure 1 depicts the 'Innovation-Decision' process whereby an individual progresses through five distinct stages before adopting or rejecting an innovation: (1) knowledge; (2) persuasion; (3) decision; (4) implementation; and (5) confirmation. According to Rogers (1995, p. 162) "knowledge occurs when an individual is exposed to an innovation's existence and gains an understanding of how it functions" and "persuasion occurs when an individual forms a favourable or unfavourable attitude towards the innovation". These two aspects of the model as they applied to teachers were the main focus of the study. 
Our study was designed to investigate the knowledge stage of this framework and if an increase in knowledge would persuade teachers to have a more favourable opinion of MT. Feedback from teachers would then inform future work on this innovation, specifically what information needs to be provided or what actions would need to be undertaken to guide teachers through each stage of the innovationdecision process. Teachers were chosen for questioning for two key reasons. Firstly, in terms of curricular innovation and reform, teachers are considered to be the key agents of change (Rekkor et al., 2013). If an innovation is to be successful, then teachers need to be directly involved and have an opportunity to create a shared understanding of the innovation in question. Involvement of teachers at the start of this initiative would achieve this. Furthermore, it has been noted that teachers accept, modify, and reject innovations on the basis of their suitability to the needs of their students and classrooms (Rekkor et al., 2013). As a result, teachers would be best placed to understand how their pupils might feel about MT, but also whether MT aligns with the dispositional and attitudinal aims of the new curriculum. By questioning teachers, we aimed to also gain an idea of the most appropriate primary year group where the concept of antibiotic resistance and the benefits of using medicinal maggots could be realistically and beneficially introduced. These actions would hopefully maximise the design and future implementation of any curricular initiative involving the teaching of MT in Welsh schools. 


\section{Methodology}

Our study involved five Welsh Primary Schools which we selected to include children with a mix and range of backgrounds, abilities and support levels as designated by the Welsh Government. Our study methodology was survey research and consisted of a paper-assessed questionnaire. The questionnaire consisted of questions with a choice of three closed answers indicated by a very simple nominal tick box answer scale (Yes/No/Not sure). This type of design methodology is often used to research opinion and explore human behaviour (Ponto, 2015). We met with headteachers from each of the five schools to explain the project, to identify participant teachers and hand them a set of information sheets, consent forms and questionnaires for teachers to fill in and return.

In Wales, , children may attend a foundation year of learning in Primary Schools at the age 4. They then enter Year One of Primary School at age 5-6 years. By the time they reach Year Six, they are between10-11 years old. Our questionnaire was designed to assess teachers' opinions on how aware they thought children of different ages would be, if introduced to certain key words and concepts related to wounds, infections, antibacterial resistance and maggot treatment. Also, we asked teachers how children might feel about maggots. Additionally, at the end of the questionnaire, we asked teachers to answer five open-ended questions on their own thoughts about introducing such issues at Primary level.

\section{Pupil Awareness of terminology}

Teachers were asked to assess pupil awareness of a series of important terminology 
related to the teaching of $\mathrm{MT}$ (Table 1$)$.

\section{Pupil perception}

We formulated a series of questions for teachers to assess what they thought pupil perception about maggots might be (Table 2)

\section{Teacher perception}

We asked teachers to answer the following five open-ended questions to assess how they themselves felt about the potential introduction of maggots and maggot therapy into their lessons and whether they thought that children might find this interesting or fun

1. In your opinion, what would be the most appropriate year to introduce maggots, microbes and maggot therapy into your lessons?

2. Do you think it would be possible to introduce maggots, microbes and maggot therapy into your lessons?

3. Would maggots, microbes and maggot therapy be something you would be interested in introducing into your lesson plan?

4. Do you think maggots, microbes and maggot therapy is something that would interest your pupils?

5. Would your pupils find learning about maggots, microbes and maggot therapy fun?

The whole questionnaire was prepared so it would necessitate no longer than 10 20 minutes for each teacher to complete. Data encryption took place to fully anonymise the dataset. 


\section{Data analysis}

Analysis of the questionnaire consisted of descriptive statistics based on the results obtained. Statistical analysis was undertaken in EXCEL and SPSS Version 22 for Windows. Any inferential statistical differences between the responses were assessed using a paired samples ' $\mathrm{t}$ ' test and statistical significance ( $P$ value) was set as $p \leq$ 0.05 .

\section{Ethical approval}

Ethical approval for this study was gained from the College of Human and Health Sciences Research Ethics Committee. 


\section{Results}

Thirty-three teachers across five primary schools responded to the questionnaire. In a few cases, teachers did not respond to all questions and these were designated as 'not applicable' responses throughout the dataset.

\section{Pupil Awareness of key terminology}

Table 3 shows the results of teacher's opinions of pupil awareness of key terms. The results showed that over three-quarters of teachers felt that words such as "insect" and "germs" would be well understood by all year groups. Teachers felt that children in younger year groups would be less aware of what a "maggot" was, and only

$51.5 \%$ of teachers said that children in Year 3 (ages 7-8) would know what this was. Additionally, teachers felt that younger years would also be less aware of terms "bacteria" or "antibiotics", but as children progressed through the years teachers increasingly felt that awareness of these terms would be achieved $(78.8 \%$ and $75.8 \%$ for year 6 respectively). With regards to the most complex terminology "antibacterial resistance", no teachers felt that pupils in Years 1-2 (age 5-7) would have an awareness of this (Table 3). This percentage, however, rose steadily for increasing year groups, so by the time pupils got to Year 5 and Year 6 (ages 9-11), $39.4 \%$ and $48.5 \%$ of teachers respectively, felt that pupils would be aware of antibacterial resistance.

\section{Pupils perception of maggots}


A range of questions were asked to gauge what teachers thought pupil's perceptions of maggots would be (Table 4).

Across all five primary school years, $40 \%-45 \%$ of teachers consistently thought that their pupils would feel squeamish about maggots. Teachers did not feel that this feeling would alter with age of pupil.

\section{Dislike and disgust}

Interestingly, when asked if teachers thought that children would "like" maggots, more teachers felt that younger children would. As the age of children increased, teachers thought that pupils would begin to dislike maggots more, (for example 46.9\% teachers said Year 1 pupils would like them compared to 33.3\% teachers thinking children in Year 5 would (Table 4) This would indicate that teachers consider that as pupils progress through school years, their perception of maggots changes to a more negative one. This was also reflected when questioned about disgust. Teachers felt that maggots would be less disgusting for the youngest children. For example, 22.6\% teachers indicated that Year 1 pupils would find maggots disgusting, compared to $34.4 \%$ for year 4 , with the percentage getting slightly lower for years 5 and 6 (28.1\% and $31.3 \%$ respectively, Table 4$)$.

\section{Fear}

Interestingly, in response to the feeling of being afraid of maggots, teachers also felt that younger children would have less fear. A few teachers (12.1\%) thought children in year 2 would be scared, but more (32.3\%) felt that pupils in Year 6 would be 
scared, indicating that teachers believed that fear (of maggots) would increase with school age of the child.

\section{Teachers' own perceptions}

The final survey questions were directed at teachers themselves who were asked to tell us their own opinions about various aspects of incorporation and teaching of MT into their lessons (Table 5a-c)

Response to the first open-ended question was very mixed (Table 5a) with teachers divided on what year they thought would be the best year to introduce such concepts as maggots, microbes and maggot therapy into lessons. Indeed, a proportion of teachers (18.8\%) suggested introducing the pupils to these concepts at Reception level. But, with increasing year groups, a greater number of teachers felt the level would become more suitable (25\% for years 1-2 and 3-4). The most appropriate year group suggested by the highest percentage of teachers (31\%), was Year 5-6.

With regards to question 2 and 3 (Table 5b) the responses were similar and mostly very positive (83.9\% and $83.4 \%$ of teachers saying yes or possibly, respectively). Importantly, a percentage of teachers (16.1\%) felt that it would not be possible for them to introduce these concepts to pupils. Furthermore, an almost equal number $(16.7 \%)$ said that they would not be interested in introducing MT to their lesson plan, indicating a degree of reluctance by some teachers to incorporate the teaching of maggots and maggot therapy into their classes. 
The last two questions queried whether teachers thought their pupils would be interested in or would have fun learning about maggots and maggot therapy (Table $5 c$ ). Responses to these questions were overwhelmingly positive ( $87.5 \%$ and $96.7 \%$ teacher said "yes" or "possibly" for interest and fun respectively). Most teachers, therefore, clearly believed that their children would enjoy learning about maggots. 


\section{Discussion}

Results from this small pilot study have yielded important information on the possibility of teaching primary school children about a globally important medical issue, in line with the new Welsh Curriculum for primary schools. The majority of teachers surveyed in our study felt that antibiotic resistance, maggot therapy and learning about maggots as a beneficial insect, were concepts that could be taught at primary school level. Teachers were willing to introduce these topics into their classrooms in line with the updated Welsh curriculum. Most teachers felt that the appropriate year to do this would be years 5 and 6, but felt that children in Years 1 and 2 could also benefit from learning about maggots. However, teachers acknowledged that they would need further support to help them independently implement this particular curricular innovation into their classrooms. Specifically, overcoming the "Yuck Factor" appeared to be a key issue for teachers.

\section{Do teachers think the "Yuck Factor" exists among their students?}

Most teachers felt that children's squeamishness towards maggots would be the same for children of all ages, with teachers thinking that just under half of all pupils in all year groups would find maggots squeamish and that this would be unaffected by age of the child. This perception by teachers appears to be in line with findings from research studies exploring children's development of disgust. Studies have found that younger children will display avoidance and general negativity when faced with disgust elicitors (Stevenson et al 2010), and studies of young children's spontaneous conversations note that some children, under the age of 3 , have words related to disgust (Widen \& Russell 2013). In general, disgust is a late developing emotion, 
with children most likely not to have fully developed the emotion of disgust until age five (Rottman 2014). It seems therefore likely that primary school children (though perhaps not reception class age in the UK) have a reasonable understanding of what is 'disgusting' to them, though how sensitive individuals are to disgust will vary (ViarPaxton et al 2015).

However, teachers did feel that older children were more likely to display stronger feelings of disgust towards maggots than younger children. These results clearly indicate that teachers feel that there is a change in children's emotional response to maggots as they get older, and, by the time children reach Years 5 and Year 6, teachers indicated that children are already beginning to develop preconceived notions and negative feelings towards maggots. Indeed, ontogeny of disgust is believed to develop during the first eight years of life and several studies indicate that the disgust response becomes increasingly more pronounced in middle childhood (Rottman, 2014).

\section{Overcoming the "Yuck Factor"}

Taking into consideration Rogers' (1995) Diffusion of Innovations theory, it appears that this pilot study was successful in making teachers aware of the value of MT ('knowledge'). It was also successful in 'persuading' them to have a favourable attitude towards the inclusion of this innovation in the updated Welsh curriculum. Approximately $75 \%$ of those involved in this exploratory study indicating that they would be willing to teach MT to their students, despite their concerns about the "Yuck Factor" that they believe their students would have. Based on feedback from the teachers involved in this study, a clearer idea of what now needs to be done to 
support the adoption of this innovative application of the Welsh curriculum in classrooms has emerged.

To assist teachers in their efforts to address their students' feelings of disgust so that they can discuss the use of maggots in medicine, a classroom-based resource would be useful. Almost all teachers thought that the pupils themselves would be interested in learning about maggots and would find it fun. However, when attempting to introduce any new topic to a curriculum, teachers note that there is a lack of time to teach such lessons, and (most significantly) a lack of available of lesson plans (Ingram \& Golick 2018). Providing resources for teachers has been shown to increase the likelihood of classroom implementation and, when devised by appropriate professionals guarantees that accurate information is being used (McNulty et al, 2007). This can be seen, for example, in the success of bug investigators - a case study that enabled teachers to incorporate the teaching of improving children's knowledge about micro-organisms, hygiene and antibiotics, justifying the value of lesson packs in the field (McNulty et al, 2007).

Given the upcoming change in the curriculum which will require teachers to address the complex issue of antibiotic resistance and the success of the Love a Maggot Public Engagement campaign (In submission) in reducing feelings of disgust in children, the value of a classroom-resource pack for teachers about the role of maggots in medicine should be explored. Teachers in this study gave guidelines on the content of these packs and what children would derive most benefit from them. For example, our open questions gave teachers a chance to let us know what they thought would be the most appropriate year group to teach the concept of microbes, wound infection and maggot therapy. The highest percentage of teachers opted for 
Years 5 and 6 . As children progress through school years, a linear rise in their ability to understand, process and retain information is expected. Evidence suggests that children may sometimes be better, and particularly more flexible, learners than adults (Gopnik et al, 2017). Some studies comparing different age groups, however, have indicated that whilst children do show a steady improvement in certain abilities with age, in terms of social attribution, there is a lag effect between the ages of 6 and 9 years but, after the age of 9 , there is a year on year improvement thereafter (Hu et al, 2010). Whilst easier terms such as germs or insects would be well known by year 1, teachers of all year groups indicated that awareness of slightly more complex keywords would increase with age of each year group in all cases, being best at years 5 to 6 . Having an awareness of antibacterial resistance, however, was felt by most teachers to only be possible by pupils in years 5 to 6 .

Results of this study have provided us with useful data which may help with the development of a lesson pack, differentiated by year and piloted among a small number of schools. We hope that this pack could be a means to help facilitate the introduction of wounds, bacteria, antibacterial resistance and medicinal maggots into the curriculum, and to provide teachers with the best resource tool. It is also hoped that the availability of this lesson pack will help teachers with the 'innovationdecision' process outlined by Rogers (1995, p. 162). The presence of this resource pack may allow teachers to 'engage in activities that lead to a choice to adopt or reject the innovation'. This will allow teacher to advance through stage 3 ('Decision') and Stage 4 ('Implementation') of Rogers' (1995) framework. However, future research would need to be conducted to evaluate the content of these resource packs to maximise student learning and to ensure teacher adoption. 


\section{Concluding remarks}

Currently maggots and maggot therapy are not subjects that are taught within the primary (or secondary) school curriculum in Wales alongside the grand challenge of global antibacterial resistance. Education on antibiotic resistance, and the properties of maggots in wound healing and disinfection of resistant species of bacteria, should perhaps be introduced at school level. Results of our pilot investigation suggest the need to explore this further since teachers felt it could be taught to children in primary years. There could not be a better and more urgent time to bring real world issues relevant to health and the environment to children in schools. If innovative topics like this are incorporated and embedded in the curriculum, primary school children would be equipped with some basic knowledge of hugely important issues such as the potentially humanity-threatening issue of antibacterial resistance, as well as the potential benefit of turning back to nature and beneficial creatures such as medicinal maggots, to help solve such crises. Indeed, if maggot therapy could be introduced early in the school curriculum, this would help to arrest the development or formation of any negative perceptions of maggots as (disgusting and revolting creatures), and instead promote them as a beneficial and useful insect. This would ensure that future generations of children could, through education, become aware and more accepting of maggot treatment, a treatment which may well be offered to them or their families in later years, and which could potentially, naturally and quickly cleanse and heal their wounds or save infected limbs from amputation. 


\section{Funding}

This pilot project was funded by an Internal Swansea University School of Education grant awarded to loan Humphreys.

\section{Acknowledgements}

Huge thanks to Dr Clare Lehane for her advice and input into this project and manuscript.

\section{Disclosure statement}

All authors declare no conflict of interest. 


\section{References}

Borgi M \& Cirulli F. (2015) Attitudes toward Animals among Kindergarten Children: Species Preferences, Anthrozoös: A multidisciplinary journal of the interactions of people and animals, 28:1, 45-59

Davey, G.C.L (1994) Self-reported fears to common indigenous animals in an adult UK population: the role of disgust sensitivity. British Journal of Psychology 85, 541 554

Dumville, J. C., Worthy, G., Bland, J. M., Cullum, N., Dowson, C., Iglesias, C., Mitchell, J. L., Nelson, E. A., Soares, M. O., Torgerson, D. J., VenUS II team Larval therapy for leg ulcers (VenUS II): randomised controlled trial. BMJ (Clinical research ed.), (2009). 338, b773. doi:10.1136/bmj.b773

Fančovičová, J., Prokop, P. (2017) Effects of Hands on activities on conservation, disgust and knowledge of Woodlice. EUASIA Journal of Mathematics, Science and Technology Education 14, 10. 721-729

Gieroń, M., Słowik-Rylska, M., and Kręcisz, B. (2018). Effectiveness of maggot debridement therapy in treating chronic wounds - review of current literature. Medical Studies/Studia Medyczne, 34(4), pp.325-331. 
Gopnik A, O'Grady S, Lucas CG, Griffiths TL, Wente A, Bridgers S, Aboody R, Fung H, Dahl RE. (2017) Changes in cognitive flexibility and hypothesis search across human life history from childhood to adolescence to adulthood. Proc Natl Acad Sci U S A. 2017 Jul 24;114(30):7892-7899.

Hu, Z, Chan, R.C.K. McAlonan G.M. (2010) Maturation of social attribution skills in typically developing children: an investigation using the social attribution task. Behavioral and Brain Functions, 6 (2010), p. 10

Ingram, E \& Golick, D. (2018) The six-legged subject: A survey of secondary science teachers' incorporation of insects into U.S. Life science instruction. Insects 9, 32

Jones J, Green J, Lillie A K. (2011) Maggots and their role in wound care. Br J Community Nursing 16: S24-33

Lorenz. A.R., Libarkin, J.C., Ording, G.J., (2014) Disgust in response to some arthropods aligns with disgust provoked by pathogens. Global Ecology and Conservation 2, 248-254

$\underline{\text { Malekian A, Esmaeeli Djavid G }}, \underline{\text { Akbarzadeh K }}$, Soltandallal M $, \underline{\text { Rassi Y }}, \underline{\text { Rafinejad }}$ $\underline{\text { J }}$ Rahimi Foroushani A, Farhoud A, Bakhtiary R, Totonchi M. (2019) Efficacy of 
Maggot Therapy on Staphylococcus aureus and Pseudomonas aeruginosa in Diabetic Foot Ulcers: A Randomized Controlled Trial. J Wound Ostomy Continence Nurs. 2019 Jan/Feb;46(1):25-29.

McNulty, C., Bowen, J., Gelb, D. and Charlett, A. (2007), "The Bug Investigators" Health Education, Vol. 107 No. 1, pp. 10-26

Ponto J. (2015). Understanding and Evaluating Survey Research. Journal of the advanced practitioner in oncology, 6(2), 168-171.

Prokop R., Randler, C (2018). Biological predispositions and individual differences in human attitudes toward animals. In: Ethnozoology, Animals in our lives. Edited by Alves, RRN, Albuquerque UP. Academic Press

Randler, C., Hummel, E., Prokop, P. (2012) Practical work at school reduces disgust and fear of unpopular animals. Society \& Animals, 20, 61-74

Rekkor, S., Ümarik, M. \& Loogma, K. (2013). Adoption of national curricula by vocational teachers in Estonia. Journal of Vocational Education \& Training, 65(4), 489-506 
Rogers, E. M. (1995). Diffusion of innovations (4 ${ }^{\text {th }}$ Edition). New York: Free Press.

Rottman, J, (2014) Evolution, Development and the emergence of disgust.

Evolutionary psychology 12, 417-433

Sandelowski M. (2010) What's in a name? Qualitative description revisited. $\underline{\text { Res }}$ Nursing Health. Feb;33 (1): 77-84.

Sherman R. A. (2014). Mechanisms of maggot-induced wound healing: what do we know, and where do we go from here? Evidence-based complementary and alternative medicine: eCAM, 2014, 592419. doi:10.1155/2014/592419

Steenvoorde, P, Buddingh, TJ, van Engeland, A, Oskam, J (2005) Maggot therapy and the "yuk" factor: an issue for the patient?. Wound Repair Regen . ;13 (3): 350352.

Stevenson, R.J., Oaten, M., Repacholi, B.M., Wagland, P. (2010) Children's response to adult disgust elicitors: Development and Acquisition. Developmental Psychology, 46(1), 165-177

Sumner, S. , Law, G. and Cini, A. (2018), Why we love bees and hate wasps. Ecological Entomology, 43: 836-845. 
Ventola C. L. (2015) The antibiotic resistance crisis: part 1: causes and threats. P \& T : a peer-reviewed journal for formulary management. 40(4), 277-83.

Viar-Paxton, M.A., Ebesutani, C., Kim, EH., Olldendick, T., Young, J., Olatunji, B.O. (2015) Development and initial validation of the Child Disgust Scale. Psychological Assessment 27, 1082-1096

Widen, S.C., Russell, J.A. (2013) Children's recognition of disgust in others. Psychological Bulletin, 139, 271-299

Wust-Ackermann, P., Vollmer, C., Itzek-Greulich, H. \& Randle, C., (2018). Invertebrate disgust reduction in and out of school and its effects on state intrinsic motivation. Palgrave Communications 4, article number 81

Yan L, Chu J, Li M, Wang X, Zong J, Zhang X, Song M, Wang S.(2018) Pharmacological Properties of the Medical Maggot: A Novel Therapy Overview. Evid Based Complement Alternat Med. May 3;:4934890. doi: 10.1155/2018/4934890. PMID: 29853956; PMCID: PMC5960508. 